\title{
Ocorrência generalizada do Lettuce mottle virus em três regiões produtoras de alface comercial do Estado de São Paulo
}

\author{
Renate Krause-Sakate ${ }^{1}$, Ana Carolina Firmino ${ }^{1 *}$, Adriana Salomão Jadão ${ }^{1}$, Marcelo A. Pavan ${ }^{1}$, Norberto da Silva ${ }^{1}$, \\ Sérgio Minoru Hanai ${ }^{2}$, Roberto Hiroto Anbo $^{2}$, Thomas Nietzsche ${ }^{3}$
}

${ }^{1}$ UNESP- Universidade Estadual Paulista, Faculdade de Ciências Agronômicas, Departamento de Produção Vegetal/Defesa Fitossanitária, 18603970, Botucatu, SP.; *Bolsista PIBIC/CNPq; ${ }^{2}$ Tomatec, Agro comercial Ltda, Rua Sylvia da Silva Braga, 972 - Jd. Sta. Mônica, 13082-080, Campinas, SP.; ${ }^{3}$ Sindicato Rural de Mogi das Cruzes, Rua Ipiranga, 1535, 08730-000, Mogi das Cruzes, SP.

Autor para correspondência: Renate Krause Sakate,e-mail: renatekrause@fca.unesp.br

Data de chegada:08/03/2006. Aceito para publicação em:13/03/2007

\section{ABSTRACT}

Krause-Sakate, R; Firmino, A.C.; Jadão, A.S.; Pavan, M.A.; Silva, N.; Hanai, S.M.; Anbo, R.H.; Nietzsche, T. Ocorrência generalizada do Lettuce mottle virus em três regiões produtoras de alface do Estado de São Paulo. Summa Phytopathologica, v.34, n.1, p.88-89, 2008

Os sequivírus são vírus isométricos transmitidos por afídeos. Lettuce mottle virus (LeMoV), um provável sequivirus foi descrito no Brasil em 1982 e causa sintomas de mosaico semelhantes aos observados pelo Lettuce mosaic virus (LMV). Um levantamento para ocorrência do LeMoV nos campos de produção de alface de três diferentes regiões do Estado de São Paulo (Mogi das Cruzes, Campinas e Bauru) foi realizado durante 2002 a 2005. RNA total foi extraído e utilizado na detecção, em RT-PCR, com oligonucleotídeos específicos para o LeMoV. Do total de 1362 amostras, $137(10,05 \%)$ foram positivas para o LeMoV. Infecção mista com o LMV foi verificada em 43 amostras $(31,4 \%)$. Foi verificada a ocorrência do LeMoV nas três diferentes regiões analisadas, porém sua ocorrência foi baixa nas diferentes épocas do ano.

Additional keywords: sequivirus

\section{RESUMO}

Krause-Sakate, R; Firmino, A.C.; Jadão, A.S.; Pavan, M.A.; Silva, N.; Hanai, S.M.; Anbo, R.H.; Nietzsche, T. Widespread occurrence of Lettuce mottle virus on three lettuce producing areas from São Paulo State. Summa Phytopathologica, v.34, n.1, p.88-89, 2008

Sequiviruses are isometric aphid-borne plant viruses. Lettuce mottle virus (LeMoV), a putative sequivirus was first described in Brazil on 1982 causing similar mosaic symptoms as Lettuce mosaic virus (LMV). A survey for the occurrence of LeMoV on open field conditions was carried out during 2002 to 2005 on Mogi das Cruzes, Campinas and
Bauru in São Paulo state. Total RNA was extracted and used on RT-PCR with specific LeMoV primers. On 1362 samples tested, 137 (10,05\%) were positive for LeMoV. Mixed infections with LMV was observed on 43 samples $(31,4 \%)$. The presence of LeMoV was observed in the three different regions, but with low incidence during the year.

\section{Palavras chave: sequivirus}

A alface (Lactuca sativa L.) pertencente à família Asteraceae, é considerada a folhosa de maior consumo mundial. Esta cultura é atacada por vários patógenos dentro os quais destacam-se os vírus. O Lettuce mosaic virus (LMV), pertencente à família Potyviridae, gênero Potyvirus é considerado um dos mais destrutivos e encontra-se distribuído em todo mundo (7).

Um segundo vírus que infecta a cultura é o Lettuce mottle virus, LeMoV, um provável sequivirus (5). A família Sequiviridae é formada por vírus de partículas isométricas, com aproximadamente $25-30 \mathrm{~nm}$ de diâmetro. O genoma destes vírus contém uma única fita de RNA senso positivo, sendo esta família constituída pelos gêneros Sequivirus e Waikavirus, onde o genoma dos waikavirus é poliadenilado e dos sequivirus não (4). O gênero Sequivirus é formado pelo Parsnip yellows fleck virus - PYFV e Dandelion yellow mosaic virus - DaYMV (4) sendo este último relatado infectando plantas de alface em diferentes países da Europa $(2,6)$. Sequências nucleotídicas parciais do DaYMV e LeMoV já são conhecidas, indicando possivelmente tratar-se de duas espécies distintas infectando alface na Europa e América do Sul, respectivamente (5).

No Brasil, o primeiro relato do LeMoV ocorreu possivelmente no
Distrito Federal (9). Os sintomas induzidos pelo LeMoV em alface incluem o mosqueado e o mosaico, podendo dependendo do cultivar ser semelhantes àqueles causados pelo LMV, tornando difícil a distinção desses dois vírus com base somente na sintomatologia (5). Não há indícios da transmissão do LeMoV via semente em cultivares de alface (3). Antisoros foram produzidos para o $\operatorname{LeMoV}(3,10)$, porém com baixa eficiência de detecção possivelmente devido à baixa concentração deste vírus em seus hospedeiros.

Oligonucleotídeos específicos para o $\mathrm{LeMoV}$ foram descritos por Jadão (5) e permitem a diagnose segura deste vírus em amostras de alface. Utilizando estes oligonucleotídeos, foi verificada a ocorrência do LeMoV em campos de produção comercial de alface nas regiões de Campinas, Mogi das Cruzes e Bauru no Estado de São Paulo. As coletas foram trimestrais, tendo sido analisadas um total de 1362 amostras de alface com sintomas de mosaico ou mosqueado. Parte das amostras foi dessecada com cloreto de cálcio anidro e armazenadas a $4^{\circ} \mathrm{C}$ e outra teve o seu RNA extraído pelo método de Bertheau et al (1).

A RT-PCR para o LeMoV foi realizada com os oligonucleotídeos Lmo3 (5' ACATGAGCACTAGTGAGG 3') e Lmo4 (5' AGATAGAGCCGTCTGGCG 3') segundo protocolo descrito por 

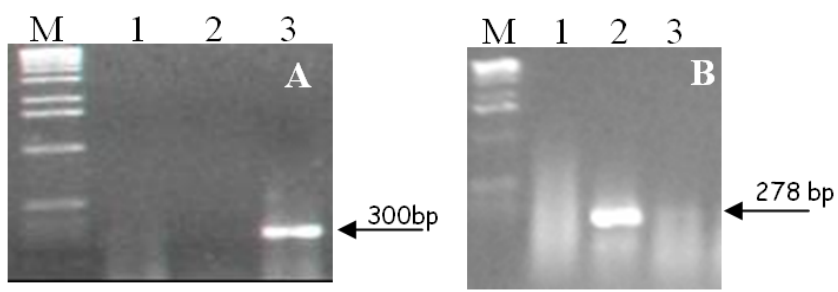

Figura 1: Perfil eletroforético dos fragmentos amplificados com os oligonucleotídeos Lmo3/Lmo4 (A) para LeMoV e 08894p/09171m (B) para LMV onde 1: controle negativo; 2: amostra LeMoV (-) e $\operatorname{LMV}(+)$; 3 : amostra LeMoV (+) e LMV (-). M: marcador de comprimento $1 \mathrm{~Kb}$ DNA ladder, Invitrogen.

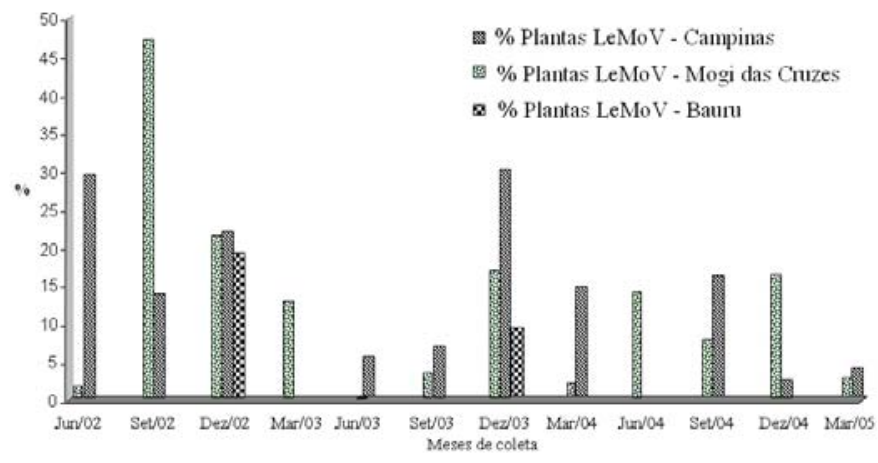

Figura 2: Porcentagem de plantas infectadas com LeMoV nas três regiões de coleta.

Jadão (5). O fragmento de aproximadamente $300 \mathrm{pb}$ foi eficientemente amplificado somente apartir das amostras infectadas por LeMoV (Figura 1). As amostras também foram analisadas para presença do LMV utilizando-se os oligonucleotídeos $08897 \mathrm{p} / 09171 \mathrm{~m}$ conforme descrito por Krause-Sakate et al. (7). Do total de 1362 amostras testadas, somente $137(10,05 \%)$ foram positivas para o LeMoV, tendo sido verificada ocorrência deste vírus nas três regiões analisadas e durante as diferentes épocas do ano (Figura 2). Infecção mista com o LMV foi verificada em 43 amostras $(31,4 \%)$. Parte das amostras negativas para o LeMoV encontrava-se infectada pelo LMV (371 amostras), não tendo sido nas demais diagnosticada a espécie viral presente.

Apesar do LeMoV em média ter sido detectado em menos de $15 \%$ das amostras coletadas, em Campinas e Mogi das Cruzes este vírus foi encontrado praticamente durante todo o ano, e com picos de ocorrência elevada, como no caso de setembro de 2002 onde foram verificados mais de $45 \%$ das amostras positivas para este vírus na região de Mogi das Cruzes (Figura 2). Curiosamente na região de Bauru o LeMoV somente foi verificado em dezembro de 2002 e 2003.

A forma de disseminação do LeMoV no campo ainda não é clara. Os poucos vírus da família Sequiviridae até então estudados não são transmitidos via semente, pólen, por contato entre plantas ou com instrumentos contaminados (5). Referente ao gênero Sequivirus, muitas informações ainda são restritas principalmente devido à existência de apenas uma espécie (PYFV) completamente caracterizada neste gênero. A transmissão do PYFV por afídeos ocorre de maneira semipersistente, sendo que este necessita do Anthriscus yellows virus, um waikavirus como vírus auxiliar (4). Marinho (10) verificaram que o isolado de LeMoV estudado na década de 80 foi transmitido pelo afídeo Hyperomyzus lactucae. Não é possível afirmar que os mesmos isolados de LeMoV encontrados hoje no campo também sejam transmitidos por esta espécie de afídeos. Experimentos de transmissão via afídeos realizados com o isolado de LeMoV AF-197, coletado na região de Campinas, demonstraram que este não foi transmitido por afídeos.

Além do Brasil, o LeMoV também é encontrado no Chile. Estudo semelhante demonstrou que a ocorrência do LeMoV neste país é bastante baixa, tendo sido verificado em 1/42 e 3/101 plantas nos anos de 2002 e 2003 respectivamente (8). A alta identidade (97\%) entre os isolados brasileiro e chileno, na porção analisada, indicou uma possível origem comum de ambos isolados, mas que hoje é dificilmente explicada pelo fato da transmissão por sementes não ter sido comprovada para o LeMoV e pela própria barreira que a Cordilheira dos Andes oferece para migração de vetores.

\section{AGRADECIMENTOS}

Os autores agradecem a Fundação de Amparo à Pesquisa do Estado de São Paulo (FAPESP) o suporte financeiro para a realização deste trabalho (Processo: 01/07140-5) e ao Centro Nacional de Pesquisa e Desenvolvimento $(\mathrm{CNPq})$ pela bolsa de iniciação científica concedida a Ana Carolina Firmino.

\section{REFERÊNCIAS BIBLIOGRÁFICAS}

1. Bertheau, Y.; D., Frechon, I.K. Toth ; L.J. Hyman. DNA amplification by polymerase chain reaction (PCR). In: Perombelon, M.C.M. e van der Wolff, J.M. Methods for the detection and quantification of Erwinia carotovora subsp. atroseptica on potatoes. Scottish Crop Research Institute Occasional Publication. 1988.

2. Bos,L.; Huijberts, N., Huttinga,H., Maat,D.Z. Further characterization of dandelion yellow mosaic virus from lettuce and dandelion. Netherland Journal Plant Pathology, Wageningen, v.89, p.207-222. 1983 .

3. Chaves, A.L.R. Caracterização de um vírus isométrico causador de mosqueado em alface (Lactuca sativa L.). 1999. 120f. Tese (Mestrado em Proteção de Plantas) - Faculdade de Ciências Agronômicas, Universidade Estadual Paulista, Botucatu.

4. Fauquet, C.M., Mayo, M.A., Maniloff, J., Desselberger, U. \& Ball, L.A. Virus Taxonomy: Eighth Report of the International Committee on Taxonomy of Viruses. Elsevier Academic Press, San Diego, 2005. 1259p.

5. Jadão, A.S. Caracterização parcial e desenvolvimento de oligonucleotídeos específicos para deteção de sequivírus infectando alface. 2004. 126f. Tese (Doutorado em Proteção de Plantas) - Faculdade de Ciências Agronômicas, Universidade Estadual Paulista, Botucatu.

6. Kassanis, B. A virus attacking lettuce and dandelion. Nature, London, v.154, n.6, 1944.

7. Krause-Sakate, R.; Le Gall, O.; Fakhfakh, H.; Peypelut, M.; Marrakchi, M.; Varveri, C.; Pavan, M.A.; Souche, S.; Lot, H.; Zerbini, F.M.; Candresse, T. Molecular characterization of Lettuce mosaic virus field isolates reveals a distinct and widespread type of resistancebreaking isolate: LMV-Most. Phytopathology, St. Paul, v. 92, n.5, p.563-572, 2002.

8. Krause-Sakate, R.; Jadão, A. S.; Firmino, A. C.; Pavan, M.A.; Zerbini, F.M.; Rosales, M.I.; Bustamente, P.; Le Gall, O. First Report of a Lettuce infecting Sequivirus in Chile. Plant Disease, St. Paul, v.89, n. 10, p.1129, 2005

9. Marinho, V.L.; Kitajima, E.W.; Lin, M.T. \& Costa, C.L.. Caracterização do vírus do mosqueado da alface. Fitopatologia Brasileira, Brasília, v.7, n.3, p.543, 1982.

10. Marinho, V.L.A.; Lin, M.T.; Kitajima, E.W. Purificação e sorologia do vírus do mosqueado da alface. Fitopatologia Brasileira, Brasília, v.11, n.3, p.937-935, 1986. 